\title{
Oxygen-Dependent Reversible Inhibition of Mitochondrial Respiration by Nitric Oxide
}

\author{
Yoshiki Takehara ${ }^{1}$, Hiroko Nakahara $^{1}$, Yoko Inai ${ }^{1,2}$, Munehisa Yabuki ${ }^{1}$, Keisuke Hamazaki ${ }^{1}$, \\ Tamotsu Yoshioka ${ }^{1}$, Masayasu Inoue ${ }^{3}$, Alan A. Horton ${ }^{4}$, and Kozo Utsumi ${ }^{*}$ \\ ${ }^{1}$ Institute of Medical Science, Center for Adult Diseases, Kurashiki, Kurashiki 710, Japan, ${ }^{2}$ Doonan Institute of \\ Medical Science, Hakodate 041, Japan, ${ }^{3}$ Department of Biochemistry, Osaka City University Medical School, \\ Abeno-ku, Osaka 545, Japan, and ${ }^{4}$ School of Biochemistry, University of Birmingham, Edgbaston, Birmin- \\ gham B15 2TT, U.K.
}

Key words: nitric oxide/mitochondria/respiration/oxygen tension/energy metabolism/NOC 18/SIN-1

\begin{abstract}
Effects of nitric oxide (NO) and NO generating agents, on the electron transport system of mitochondria were examined in a study of the mechanism and physiological importance of NO in energy metabolism. In the presence of various substrates, uncoupled respiration was inhibited by NO in manner which was both dose- and oxygen tension-dependent. Simultaneously measuring changes in cytochrome absorption spectra and respiration showed that the site of action of NO is cytochrome oxidase. Similar inhibition was also brought about by 1-hydroxy-2-oxo-3,3-bis(2-aminoethyl)-1-triazene (NOC 18), an NO donor. Electron paramagnetic resonance (EPR) analysis revealed that inhibition of uncoupled respiration occurred only during the presence of NO in the reaction mixture. The inhibitory effect of NO was increased significantly by lowering the concentration of mitochondrial protein. No appreciable inhibition of respiration was observed in the presence of 3-morpholinosydnonimine (SIN-1), a peroxynitrite anion $\left(\mathrm{ONOO}^{-}\right)$generating reagent, but inhibition did occur in the presence of superoxide dismutase (SOD). These results indicate that NO reversibly interacts with mitochondria at complex IV thereby inhibiting respiration particularly under physiologically low oxygen tension and that de novo generated $\mathrm{ONOO}^{-}$may have no significant effect under the present experimental conditions.
\end{abstract}

Nitric oxide (NO), generated from L-arginine, has been identified as an important regulatory molecule in various pathophysiological processes, involving, for example, neurotransmisson, vasodilatation, inhibition of platelet aggregation and host defense $(27,31,33)$. NO readily enters cells and affects functions of organella, such as microsomes and mitochondria. In this context, endogenously generated NO has been shown to inhibit mitochondrial functions of various cells $(12,17,28,40$, 44 ) through formation of nitrosyl ferrocytochrome com-

\footnotetext{
* To whom correspondence should be addressed: Kozo Utsumi, Institute of Medical Science, Center for Adult Diseases, Kurashiki, 230 Bakuro-cho, Kurashiki 710, Japan

Tel: 086-422-2111, Fax: 086-426-8616

2 On leave from the Doonan Institute of Medical Science, 41-9, Ishikawa-cho, Hakodate 041, Japan.

Abbreviations used: DNP, dinitrophenol; EPR, electron paramagnetic resonance; Cyt. c, cytochrome c; GSH, reduced glutathione; GSNO, S-nitrosoglutathione; $\mathrm{HbO}_{2}$, oxygenated hemoglobin; MGD, $\mathrm{N}$-methyl-D-glucamine-dithiocarbamate; $\mathrm{NO}$, nitric oxide; $\mathrm{NO}_{2}$, nitrite; $\mathrm{NO}_{3}$, nitrate; NOC 18, 1-hydroxy-2-oxo-3,3-bis(2-aminoethyl)1-triazene; $\mathrm{O}_{2} \cdot{ }^{-}$, superoxide anion; $\cdot \mathrm{OH}$, hydroxyl radical; $\mathrm{ONOO}^{-}$, peroxynitrite anion; RCR, respiratory control ratio; SIN-1, 3-morpholinosydnonimine; SOD, superoxide dismutase; TMPD, tetramethylp-phenylenediamine.
}

plex $(16,24)$. NO deenergizes mitochondria, resulting in the disruption of cytosolic calcium homeostasis and thereby killing cultured hepatocytes $(26,38,39)$. NO also inhibits protein kinase $\mathrm{C}$ and the calcium-dependent proteinase, calpain, reversibly $(15,32)$. NO, at submicromolar concentration, has been shown to reversibly inhibit the activity of isolated cytochrome (Cyt) oxidase as well as the enzyme present in mitochondria and brain synaptosomes $(4,5,10,45)$. This property of NO enables mitochondria to function as a sensor for detecting oxygen concentration over the physiological range (4).

Since the reactivity of NO with molecular oxygen is fairly high, the interaction of NO with the above mentioned enzymes might occur more efficiently at low rather than high oxygen tensions. Since oxygen concentrations in mitochondria $(1-5 \mu \mathrm{M})$ are significantly lower than those in the cytosol $(10-60 \mu \mathrm{M})$, mitochondrial metabolism might be affected by NO more significantly than that in the cytosol. We previously reported that a low concentration of NO reversibly inhibited mitochondrial respiration without affecting the activity of energy transducing enzymes and that the inhibition was more marked at physiologically low oxygen tensions than at 
high tensions $(34,43)$. We also reported that NO reversibly inhibited the respiration at the cellular level in a manner of oxygen tension-dependent (21). Our present work describes a site and mechanism for the inhibition of mitochondrial respiration by NO. Kinetic analysis confirmed that Cyt c oxidase is the primary site of NO interaction in mitochondrial respiration and that a fairly large dose of $\mathrm{ONOO}^{-}$has negligible effects on mitochondrial functions. The physiological importance of changes in concentrations of NO and oxygen in the regulation of energy metabolism is discussed.

\section{MATERIALS AND METHODS}

Chemicals. Nitric oxide gas (98\%) was obtained from Teisan Co. Ltd. (Tokyo). NOC 18, SIN-1 and N-methyl-D-glucamine-dithiocarbamate (MGD) were obtained from DOJINDO LABORATORIES (Kumamoto). All other chemicals were of analytical grade and obtained from Nacalai Tesque Co. (Kyoto).

Preparation of nitric oxide solution. Nitric oxide solution was prepared at room temperature by bubbling the medium used for analyzing mitochondrial energy transducing reactions with argon gas (10 min) and then with NO gas (30 min) which had been passed previously through a $\mathrm{KOH}$ column (2 $\times 2.5 \mathrm{~cm})$ to remove nitrogen dioxide. Aliquots of the NOcontaining medium $(1.9 \mathrm{mM})$ were added to the mitochondrial suspensions using a gas-tight syringe (9).

Isolation of mitochondria. After fasting animals overnight, liver mitochondria were isolated from male Wistar rats weighing $200-250 \mathrm{~g}$ by the method of Hogeboom (19) using a medium containing $0.25 \mathrm{M}$ sucrose, $10 \mathrm{mM}$ Tris- $\mathrm{HCl}(\mathrm{pH}$ 7.4), and 0.1 mM EDTA. EDTA was omitted in the final wash and the mitochondrial preparation was suspended in a concentration at $10-20 \mathrm{mg}$ protein $/ \mathrm{ml}$ in $0.25 \mathrm{M}$ sucrose containing $10 \mathrm{mM}$ Tris- $\mathrm{HCl}, \mathrm{pH} 7.4$, at $4^{\circ} \mathrm{C}$. Mitochondrial protein was determined by Bradford's method using bovine serum albumin as a standard (3).

Measurement of oxygen uptake. Oxygen uptake was measured polarographically using a Clark type oxygen electrode fitted to a $2 \mathrm{ml}$ water-jacketed closed chamber at $25^{\circ} \mathrm{C} \mathrm{(35).}$ Isolated mitochondria $(0.5-1 \mathrm{mg}$ protein $/ \mathrm{ml})$ were suspended at $25^{\circ} \mathrm{C}$ in a medium consisting of $0.2 \mathrm{M}$ sucrose, $10 \mathrm{mM} \mathrm{KCl}$, $1 \mathrm{mM} \mathrm{MgCl}, 2 \mathrm{mM}$ sodium phosphate and $10 \mathrm{mM}$ Tris- $\mathrm{HCl}$ (pH 7.4). Uncoupled respiration was measured with either 5 $\mathrm{mM}$ glutamate, $5 \mathrm{mM}$ succinate or $1 \mathrm{mM}$ ascorbate- $10 \mu \mathrm{M}$ TMPD in the presence of either $1 \mathrm{mM}$ malonate, $1 \mu \mathrm{M}$ rotenone or $10 \mathrm{nM}$ antimycin A, respectively. The respiratory control ratio (state 3/state 4 respiration, RCR) and the ADP/O ratio were determined as described by Estabrook (14).

Determination of the redox state of the mitochondrial electron transport chain. The oxidation-reduction state of cytochromes in mitochondria was determined by means of the difference spectrum (25) between NO-treated and untreated mitochondria using a dual beam spectrophotometer (Shima- dzu UV 3000) in a thermostatically controlled cuvette equipped with an oxygen electrode and magnetic stirrer.

Electron paramagnetic resonance $(E P R)$ analysis of $M G D$ $\mathrm{Fe}^{2+}$-NO complex. The concentration of NO in the reaction mixture was determined at room temperature by a spin trapping method (29). The reaction of NO with [MGD-Fe $\left.{ }^{2+}\right]$ was examined by using EPR spectroscopy (JES-FE-1X, JEOL, Tokyo, Japan). At various times before and after adding NO, the $\left[\mathrm{MGD}-\mathrm{Fe}^{2+}\right]$ complex in water was added to the reaction mixture containing mitochondria (final concentrations of MDG and $\mathrm{FeSO}_{4}$ were $1 \mathrm{mM}$ and $20 \mu \mathrm{M}$, respectively). Aliquots of the reaction mixture were transferred into a quartz flat cell (inner size, $60 \times 10 \times 0.3 \mathrm{~mm}$ ) for EPR measurements. The instrument setting included $100 \mathrm{G}$ field scan, $30 \mathrm{~s}$ scan time, $0.1 \mathrm{~s}$ time constant, $2.5 \mathrm{G}$ modulation amplitude, 100 $\mathrm{kHz}$ modulating frequency and $25 \mathrm{mM}$ microwave power.

\section{RESULTS}

Effect of NO on electron transport of mitochondria. We previously reported that phosphorylating and uncoupled respiration were reversibly inhibited by NO especially at low oxygen concentration; oxidative phosphorylation, the $\mathrm{ADP} / \mathrm{O}$ ratio, and the respiratory control ratio returned fully to control levels after the disappearance of NO from the incubation medium. To investigate the mechanism of inhibition, the effect of NO on the mitochondrial electron transport system was examined. In the presence of glutamate and malonate, mitochondrial respiration was increased by adding dinitrophenol (DNP). The rate of uncoupled respiration was reversibly inhibited by $1 \mu \mathrm{M}$ NO; the inhibitory effect was significantly stronger at low oxygen tension than at high tension (Fig. 1a). A similar inhibition was also observed with NO in the presence of either succinate and rotenone (Fig. 1b) or ascorbate, TMPD and antimycin A (Fig. 1c). In all cases, the inhibitory effect of NO was stronger at low oxygen tension than at high tension. A similar effect of NO was also observed with mitochondria which were uncoupled by repeated freezing and thawing (data not shown). In contrast, neither $\mathrm{NO}_{2}$ nor $\mathrm{NO}_{3}$ showed such an effect even at concentrations of 1 $\mathrm{mM}$. These results indicated that the step of terminal electron transport in mitochondria, Cyt c oxidase, might be the primary site for the reversible inhibition of mitochondrial respiration by NO, which would confirm previous observations $(34,43)$.

NO-dependent reduction of mitochondrial cytochrome. To elucidate the mechanism of the reversible inhibition of respiration, the effect of NO on the absorption spectrum of cytochromes was examined. In the presence or absence of glutamate and DNP, oxygen uptake and the absorption spectrum were measured simultaneously. In the absence of NO, the mixture showed no absorption either in the presence or absence of the respira- 

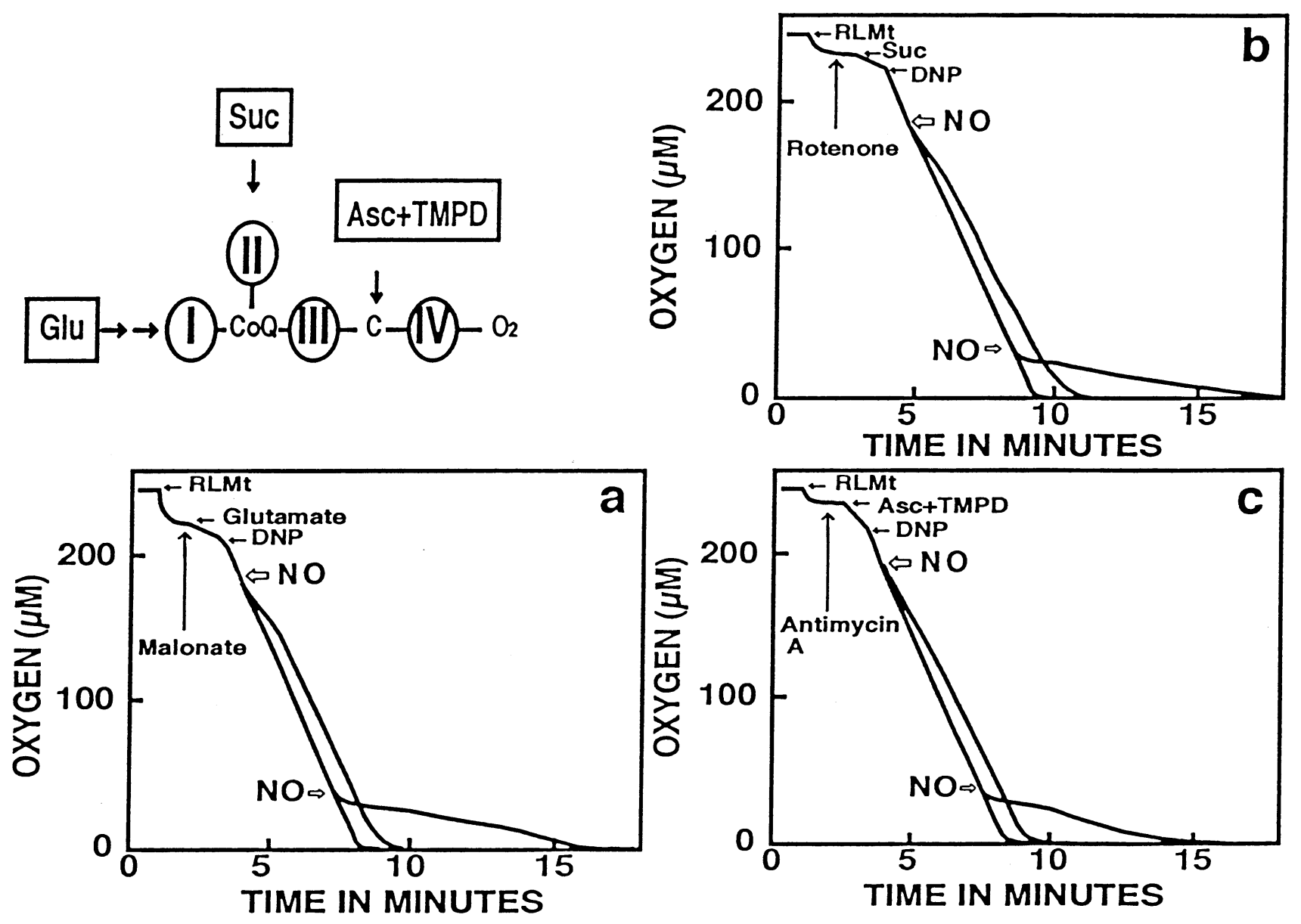

Fig. 1. Effect of NO on the uncoupled respiration of rat liver mitochondria. Oxygen consumption was measured polarographically at $25^{\circ} \mathrm{C}$ using a Clark type oxygen electrode fitted to a $2 \mathrm{ml}$ water-jacketed closed chamber. Isolated mitochondria were suspended in a medium consisting of $0.2 \mathrm{M}$ sucrose, $10 \mathrm{mM} \mathrm{KCl}, 1 \mathrm{mM} \mathrm{MgCl}_{2}$, and $10 \mathrm{mM}$ Tris- $\mathrm{HCl}\left(\mathrm{pH} \mathrm{7.4)}\right.$ at $25^{\circ} \mathrm{C}$. a, b and c show the uncoupled respiration of mitochondria in the presence of $1 \mathrm{mM}$ malonate and $5 \mathrm{mM}$ glutamate, $1 \times 10^{-7} \mathrm{M}$ rotenone and $5 \mathrm{mM}$ succinate, and $1 \times 10^{-9} \mathrm{M}$ antimycin $\mathrm{A}, 1 \mathrm{mM}$ ascorbate and $1 \times 10^{-5} \mathrm{M}$ TMPD, respectively. Concentrations of mitochondria in a, b, and c were $1,0.5$ and $0.25 \mathrm{mg} / \mathrm{ml}$, respectively. Concentrations of added NO $(\hookleftarrow)$ in a, b, and c were 1.2, 0.6 and $0.25 \mu \mathrm{M}$, respectively. Concentration of DNP used in the experiments was $2 \times 10^{-5} \mathrm{M}$. RLMt, rat liver mitochondria.

tory substrate (Fig. 2). However, various cytochromes were immediately reduced after adding NO. The spectra returned to the control state when respiration recovered. When the anaerobic state was obtained after consumption of all oxygen, all cytochromes were again reduced. The absorption spectra for the cytochromes were quite similar to that of the differential spectrum for the oxidized/reduced samples.

Effect of NO generating agent on mitochondrial respiration. To obtain an insight into the molecular mechanism for the reversible inhibition of mitochondrial respiration, the effect of NOC 18, an NO generating agent, on the uncoupled respiration was studied using succinate as substrate. Uncoupled respiration was inhibited by NOC 18 in a concentration-dependent manner. In the presence of $0.5 \mathrm{mg}$ mitochondrial protein $/ \mathrm{ml}, 2 \mathrm{mM}$ NOC 18 completely inhibited the respiration at an oxygen concentration of $6 \mu \mathrm{M}$. The inhibited respiration recovered on adding oxygen to the medium. When the inhibitory effect of NO disappeared (20 min after introduction), the rate of oxygen uptake was slightly lower (by about 20\%) than originally (Fig. 3). A similar decrease in the rate of oxygen uptake was also observed after incubation of untreated mitochondria for $20 \mathrm{~min}$ at $37^{\circ} \mathrm{C}$, suggesting a nonspecific inactivation during the incubation.

Changes in NO level in mitochondrial suspension. To determine the change in NO concentration in the incubation, the EPR signal of the MDG- $\mathrm{Fe}^{2+}$-NO adduct was monitored during the experiments. The NO level in the reaction mixture rapidly decreased at high oxygen concentration but decreased slowly over a fairly long period at low oxygen concentrations (Fig. 4). The inhibitory effect of NO was not seen when the EPR signal dis- 

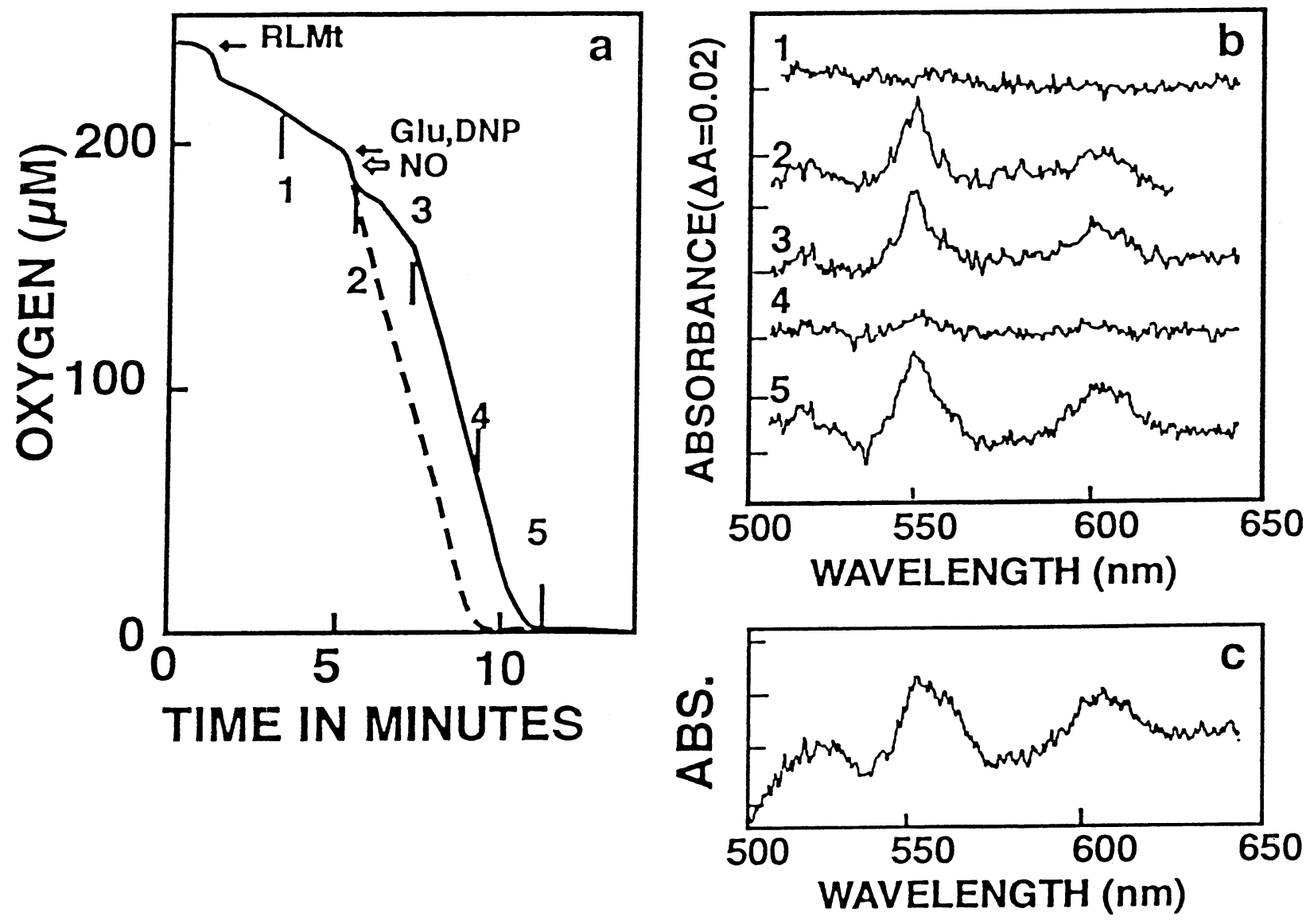

Fig. 2. Simultaneous measurement of oxygen consumption and the oxidation-reduction state of mitochondrial cytochromes. Incubation conditions were as described in Fig. 1a except for the concentrations of added NO and glutamate which were $2.7 \mu \mathrm{M}$ and $5 \mathrm{mM}$, respectively. Absorption spectra of mitochondrial cytochromes and oxygen uptake were measured using the dual beam spectrophotometer (Shimadzu UV 3000) equipped with an oxygen electrode in a thermostatically controlled cuvette holder with a magnetic stirrer. a, oxygen uptake in the presence or absence of added NO. Dotted lines show the control experiment without NO. Open arrow shows the time of NO addition. b, absorption spectrum at times 1, 2, 3, 4, and 5 in Fig. 2a; c, differential absorption spectra of mitochondria (1 mg/ml) between ferricyanide-oxidation and hydrosulfite-reduction; ABS, absorbance.

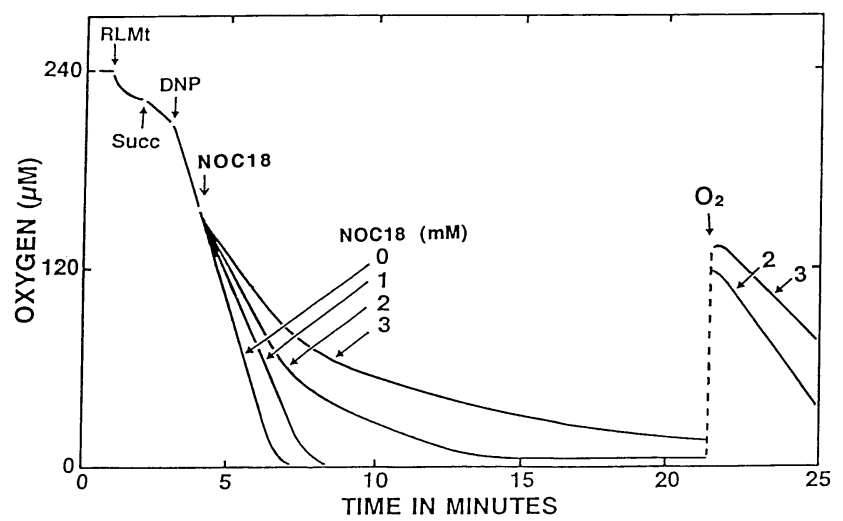

Fig. 3. Dose-dependent inhibition of mitochondrial respiration by NOC 18. Experimental conditions were as described in Fig. 1b. The concentrations of NOC 18 used was $0(0), 1$ (1), 2 (2), and $3 \mathrm{mM}(3)$. appeared.

Effect of mitochondrial concentration on the inhibitory action of NO. Interestingly, the extent of inhibition of uncoupled respiration by NO depended on the amount of mitochondrial protein in the assay mixture; the inhibition was more marked with low concentrations of mitochondria than with high concentrations (Fig. 5). Of course, we can see the inhibited respiration of mitochondria by higher concentration of NO, such as $2 \mu \mathrm{M}$ NO, even when the mitochondrial concentration was $10 \mathrm{mg}$ protein $/ \mathrm{ml}$. This observation suggested that NO might also interact with mitochondrial component(s) other than Cyt oxidase and undergo inactivation.

Effect of SIN-1 on mitochondrial respiration. It is well documented that NO rapidly reacts with superoxide $\left(\mathrm{O}_{2}{ }^{-}\right)$thereby generating stable ONOO ${ }^{-}$(2). Mitochondria have been known to generate $\mathrm{O}_{2}{ }^{-}$particular- 

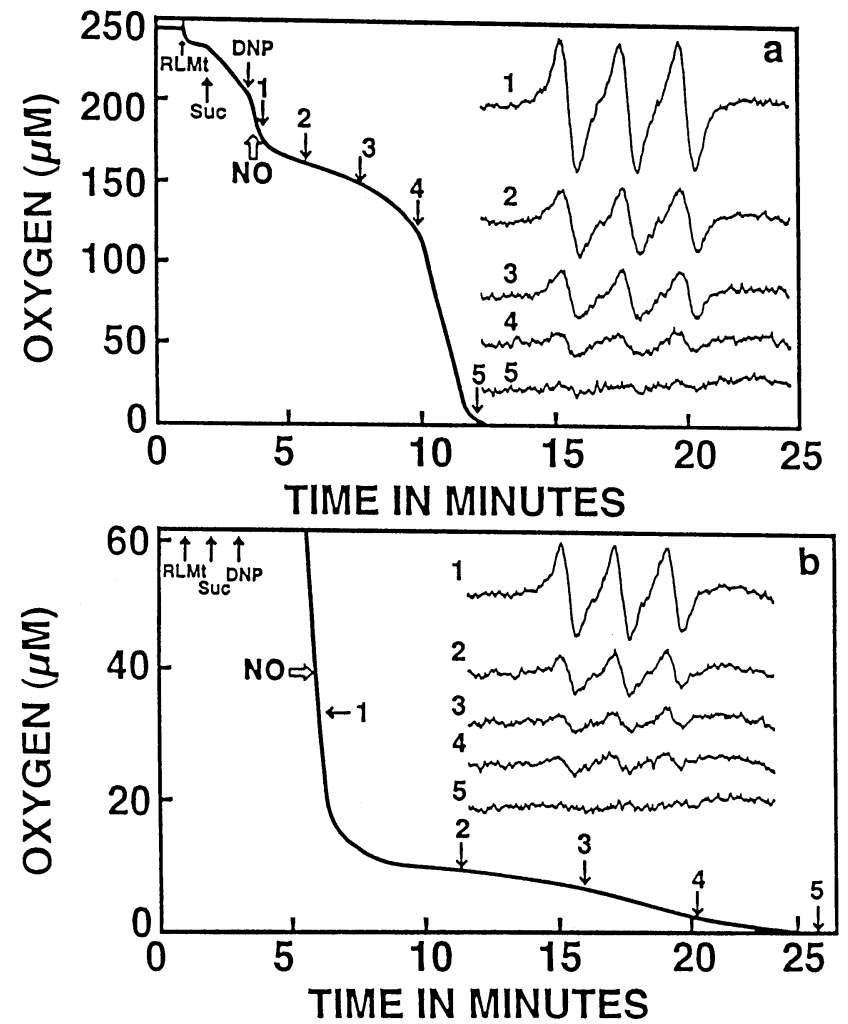

Fig. 4. Changes in NO level in reaction mixtures. Mitochondria $(0.5 \mathrm{mg} / \mathrm{ml})$ were suspended in $0.2 \mathrm{M}$ sucrose, $10 \mathrm{mM} \mathrm{KCl}, 1 \mathrm{mM}$ $\mathrm{MgCl}_{2}, 2 \mathrm{mM}$ sodium phosphate, and $10 \mathrm{mM}$ Tris- $\mathrm{HCl}(\mathrm{pH} \mathrm{7.4)}$ at $25^{\circ} \mathrm{C}$. At the indicated times after adding 5 and $2 \mu \mathrm{M}$ NO at high and low oxygen concentrations, respectively. NO concentration during the incubation was monitored by EPR method using $1 \mathrm{mM}$ MDG and $20 \mu \mathrm{M} \mathrm{FeSO}_{4}$. Numbers (1-5) for EPR spectrum correspond to those in the oxygen consumption curves. a, effect of $\mathrm{NO}$ at high oxygen tension; $b$, the effect of NO at low oxygen tension.

ly when their electron transport chain is inhibited (8). To investigate the possible involvement of $\mathrm{ONOO}^{-}$in the NO-dependent inhibition of mitochondrial respiration, the effect of SIN-1, an $\mathrm{ONOO}^{-}$producing agent by releasing equimolar amounts of $\mathrm{NO}$ and $\mathrm{O}_{2} \cdot{ }^{-}$, on mitochondrial respiration was examined. The uncoupled respiration with succinate was not appreciably affected by fairly high concentrations of SIN-1 ( 300 $\mu \mathrm{M})$. However, in the presence of exogenously added SOD $(500 \mathrm{U} / \mathrm{ml})$, the respiration was markedly inhibited by SIN-1 particularly at low oxygen concentrations; the inhibitory effect depended on SIN-1 concentration (Fig. 6). In the presence of SOD, generated $\mathrm{O}_{2} \cdot{ }^{-}$ from SIN-1 was dismutated to $\mathrm{H}_{2} \mathrm{O}_{2}$ and oxygen, and cytochrome oxidase was inhibited by generated NO. These results indicated that $\mathrm{NO}$ but not $\mathrm{ONOO}^{-}$generated from SIN-1 might be responsible for the inhibition of mitochondrial respiration.

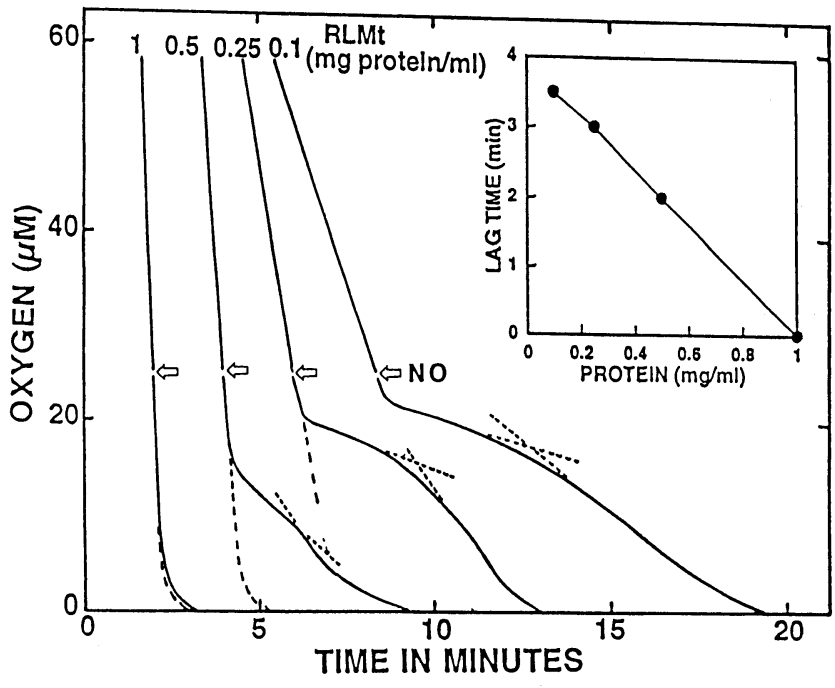

Fig. 5. Effect of mitochondrial protein concentration on the inhibitory effect of NO. Experimental conditions were as described in Fig. 2. The concentration of NO added was $0.95 \mu \mathrm{M}$. Concentrations of mitochondria were $0.1-1.0 \mathrm{mg}$ protein $/ \mathrm{ml}$. Arrows show the time points of NO addition. Insert shows the dependency of the recovery time on mitochondrial protein concentration.

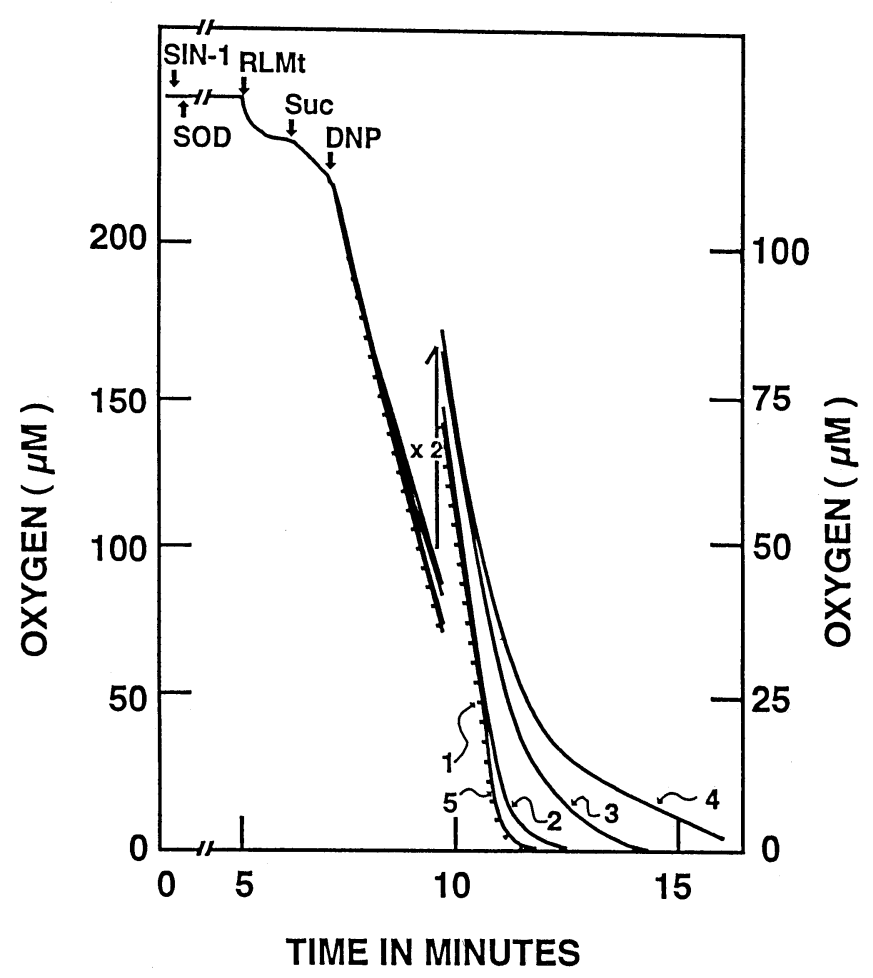

Fig. 6. Effect of SIN-1 on mitochondrial respiration. Experimental conditions were as described in Fig. 1b. Various concentrations of SIN-1 were added $5 \mathrm{~min}$ before incubation of mitochondria in the presence $(2,3,4)$ or absence $(1,5)$ of $500 \mathrm{U} / \mathrm{ml} \mathrm{SOD}$. The concentrations of SIN-1 used were $0(1), 0.1(2), 0.2(3)$ and $0.3 \mathrm{mM}(4,5)$. The dotted line (1) shows the control experiment without SIN-1. 


\section{DISCUSSION}

The work presented in this paper demonstrated that NO reversibly inhibits energy transfer reactions of mitochondria in a dose- and oxygen concentration-dependent manner. The inhibition occurred more markedly and continued longer at physiologically low oxygen concentrations than at high oxygen concentration. Since both the ADP/O ratio and the respiratory control ratio (RCR) completely recovered to control levels at certain times after inhibition, the interaction of mitochondrial constituent(s) with $\mathrm{NO}$ and/or its metabolite(s) might have occurred reversibly. Since NO inhibited mitochondrial respiration either in the presence or absence of DNP, interaction with the electron transfer system might be responsible for the inhibition. Spectrophotometric analysis suggested that NO formed a dissociable complex(s) with heme-containing proteins in mitochondria. Consistent with this notion is the report that NO forms complexes with Cyt c oxidase and complexes I and II $(11,13,18,40,47)$. Since NO equally inhibited respiration in the presence of either rotenone or antimycin A, Cyt c oxidase might be the primary site for inhibition. It should be noted that the inhibitory effect of NO increased with concomitant decreases in protein concentrations; the inhibition by $1 \mathrm{nmol} \mathrm{NO}$ was negligible at $1 \mathrm{mg}$ of mitochondrial protein but became apparent at concentrations lower than $0.5 \mathrm{mg}$. Mitochondria contain about $0.8 \mathrm{nmol}$ of heme-proteins/mg proteins (7). Thus, mitochondrial component(s) other than hemeproteins might also interact with NO. In this context, NO has been shown to form nitrosothiols (42). Since GSH is the major thiol in mitochondria and has high affinity for $\mathrm{NO}$, it might form S-nitrosoglutathione (GSNO). Assuming values of $5 \mathrm{mM}$ and $1 \mu \mathrm{l} / \mathrm{mg}$ protein for mitochondrial GSH and matrix volume, respectively $(22,30)$, about $5 \mathrm{nmol}$ of GSH would exist in $1 \mathrm{mg}$ of mitochondrial protein. Hence, significant amounts of NO used in the experiments in Fig. $5(1 \mu \mathrm{M})$ may have been trapped by mitochondrial GSH, particularly at protein concentrations higher than $0.2 \mathrm{mg} / \mathrm{ml}$. This might explain why the inhibitory effect of NO increased with a concomitant decrease in mitochondrial concentration. It should be noted that GSNO is also an NO donor which slowly releases NO (36). Thus, de novo generated GSNO might slowly release NO thereby inhibiting Cyt c oxidase (10) for a prolonged period of time. However, preliminary experiments revealed that $1 \mu \mathrm{M}$ GSNO had no appreciable effect on respiration. Although active transport of GSH into the mitochondrial matrix has been well documented, transport of GS-conjugates, including GSNO, across the inner-mitochondrial membrane has not been demonstrated. Decomposition of GSNO to NO and GSSG requires strong reducing agents, such as thiolate anions (36). Thus, the possi- ble occurrence of GSNO and its homolytic cleavage within the mitochondrial matrix needs to be studied further.

It should be noted that mitochondria generate $\mathrm{O}_{2} \cdot{ }^{-}$, particularly when the electron transfer system is inhibited (46). Preliminary experiments revealed that NOtreated mitochondria also generated $\mathrm{O}_{2} \cdot{ }^{-}(2.2 \mathrm{pmol} / \mathrm{mg}$ protein $/ \mathrm{min}$ ). Since NO rapidly reacts with $\mathrm{O}_{2}{ }^{-}$to forms toxic $\mathrm{ONOO}^{-}(1,20,23)$, the inhibition of mitochondrial respiration may be caused by $\mathrm{ONOO}^{-}$. In fact, $\mathrm{ONOO}^{-}$has been shown to inhibit functions of mitochondrial components, such as succinate dehydrogenase, ATPase and aconitase $(6,37)$. However, inhibition of these proteins by $\mathrm{ONOO}^{-}$occurred irreversibly $(11,32)$. Furthermore, cytochrome c oxidase is highly resistant to $\mathrm{ONOO}^{-}$(37). Since the inhibition by NO was completely reversible under the present experimental conditions, NO and/or its metabolite(s), other than $\mathrm{ONOO}^{-}$, might be principally responsible for the inhibition of mitochondrial respiration.

It should be noted that the lifetime of NO is significantly longer under physiologically low intracellular oxygen tensions $(10-60 \mu \mathrm{M})(13)$ than at its high concentrations. However, most experiments in vitro describing the inhibitory effects of NO were carried out under air atmospheric conditions where the oxygen concentration $(235 \mu \mathrm{M})$ is very much higher than intracellular levels. Furthermore, under aerobic conditions, NO rapidly disappears and forms various reactive species, such as $\mathrm{NO}_{2}, \mathrm{ONOO}^{-}$, and $\cdot \mathrm{OH}$. These hazardous metabolites of NO but not NO itself might result in the irreversible inactivation of mitochondrial constituents under highly aerobic conditions. However, the effect of NO might be reversible under physiological conditions and more potent, longer lasting and specific in vivo than previously observed with in vitro experiments performed under air atmospheric conditions. Since oxygen concentrations in ischemic tissues are extremely low, NO might inhibit mitochondrial energy metabolism more potently in and around ischemic areas than in non-ischemic areas. Critical roles of NO in energy metabolism in and around normal and ischemic tissues should be studied further.

Acknowledgments. This work was supported by a grant from The Japan Keirine Association.

\section{REFERENCES}

1. Beckman, J.S., Beckman, T.W., Chen, J., Marshall, P.A., and Freeman, B.A. 1990. Apparent hydroxyl radical production by peroxynitrite; implications for endothelial injury from nitric oxide and superoxide. Proc. Natl. Acad. Sci. USA, 87: 1620-1624.

2. BLOUGH, N.V. and ZAFIRIOU, O.C. 1985. Reaction of superoxide with nitric oxide to form peroxynitrite in alkaline aqueous solution. Inorg. Chem., 24: 3502-3504. 
3. BRADFORD, M. 1975. A rapid and sensitive method for the quantification of microgram quantities of protein utilizing the principle of protein-dye binding. Anal. Biochem., 72: 248-254.

4. BROWN, G.C. 1995. Nitric oxide regulates mitochondrial respiration and cell functions by inhibiting cytochrome oxidase. FEBS Lett., 369: 136-139.

5. BRown, G.C. and Cooper, C.E. 1994. Nanomolar concentrations of nitric oxide reversibly inhibit synaptosomal respiration by competing with oxygen at cytochrome oxidase. FEBS Lett., 356: 295-298.

6. Castro, L., Rodriguez, M., and Radi, R. 1994. Aconitase is readily inactivated by peroxynitrite, but not by its precursor, nitric oxide. J. Biol. Chem., 269: 29409-29425.

7. Chance, B. and Hess, B. 1959. Metabolic control mechanisms. I. Electron transfer in the mammalian cell. J. Biol. Chem., 234: 2404-2415.

8. Chance, B., Sies, H., and Boveris, A. 1979. Hydroperoxide metabolism in mammalian organs. Physiol. Rev., 59: 527-605.

9. ClanCy, R.M., LesZCZyNSKA-PiziaK, J., and Abramson, S.B. 1992. Nitric oxide, an endothelial cell relaxation factor, inhibits neutrophil superoxide anion production via a direct action on the NADPH oxidase. J. Clin. Invest., 90: 1116-1121.

10. Cleeter, M.W.J., Cooper, J.M., Darley-Usmar, V.M., MonCADA, S., and SchapIRA, A.H.V. $1994 . \quad$ Reversible inhibition of cytochrome $\mathrm{c}$ oxidase, the terminal enzyme of the mitochondrial respiratory chain, by nitric oxide. FEBS Lett., 345: $50-54$.

11. Drapier, J.C. and HibBs, Jr., J.B. 1986. Murine cytotoxic activated macrophages inhibit aconitase in tumor cells. Inhibition involves the iron-sulfur prosthetic group and is reversible. $J$. Clin. Invest., 78: 790-797.

12. Drapier, J.C. and Hibbs, Jr., J.B. 1988. Differentiation of murine macrophages to express nonspecific cytotoxicity for tumor cell results in $l$-arginine-dependent inhibition of mitochondrial iron-sulfur enzymes in the macrophage effector cells. J. Immunol., 140: 2829-2839.

13. Drapiar, J.C., Pellat, C., and Henry, Y. 1991. Generation of EPR-detectable nitrosyl-iron complexes in tumor target cells cocultured with activated macrophages. J. Biol. Chem., 266: 10162-10167.

14. EstabrooK, R.W. 1967. Mitochondrial respiratory control and the polarographic measurement of ADP: O rations. Methods Enzymol., 10: 41-47.

15. Gopalakrishna, R., Chen, Z.H., and Gundimeda, Y. 1993. Nitric oxide and nitric oxide-generating agents induce a reversible inactivation of protein kinase $\mathrm{C}$ activity and phorbol ester binding. J. Biol. Chem., 268: 27180-27185.

16. Gorren, A.C.F., Van Gelder, B.F., and WeVer, R. 1988. Photodissociation of cytochrome c oxidase-nitric oxide complexes. Ann. New York Acad. Sci., 550: 139-149.

17. Granger, D.L., Taintor, R.R., CoOK, J.L., and HibBs, Jr., J.B. 1980. Injury of neoplastic cells by murine macrophages leads to inhibition of mitochondrial respiration. J. Clin. Invest., 65: 357-370.

18. Granger, D.L. and Lehninger, A.L. 1982. Sites of inhibition of mitochondrial electron transport in macrophage-injured neoplastic cells. J. Cell Biol., 95: 527-535.

19. HoGeboom, G.H. 1955. Fractionation of cell components of animal tissues. Methods Enzymol., 1: 16-19.

20. HuIE, R.E. and Padmaja, S. 1995. The reaction of NO with superoxide. Free Rad. Res. Commun., 18: 195-199.

21. InaI, Y., Takehara, Y., Yabuki, M., Sato, E.F., AkiYama, J., Yasuda, T., Inoue, M., Horton, A.A., and Utsumi, K.
1996. Oxygen-dependent-regulation of Ehrlich ascites tumor cell respiration by nitric oxide. Cell Struct. and Funct., 21: 151157.

22. InOue, M. 1994. Free radicals. Protective mechanism. The liver, Biology and pathophysiology (Arias, I.M., ed.), Raven Press, New York, pp.443-459.

23. Ischiropoulos, H., ZhU, L., and Beckman, J.S. 1992. Peroxynitrite formation from macrophage-derived nitric oxide. Arch. Biochem. Biophys., 298: 446-451.

24. KeILIN, D. 1966. The history of cell respiration and cytochrome. London, Cambridge University Press, pp.319-335.

25. King, T.E., NiCKel, K.S., and Jensen, D.R. 1964. Iron, copper, cytochrome, and lipid contents of heart muscle preparation and heart mitochondria. J. Biol. Chem., 239: 1989-1994.

26. Kong, S.K., Choy, Y.M., and LeE, C.Y. 1994. The nitric oxide donor, sodium nitroprusside, increased intranuclear and cytosolic calcium concentration in single pu5-1.8 cells. Biochem. Biophys. Res. Commun., 199: 234-240.

27. KNowles, R.G. and MonCadA, S. 1992. Nitric oxide as a signal in blood vessels. Trends Biochem. Sci., 17: 399-402.

28. Kurose, I., Kato, S., Ishi, H., Miura, S., Suematsu, M., and Tsuchiya, M. 1993. Nitric oxide mediates lipopolysaccharideinduced alteration of mitochondrial function in cultured hepatocytes and isolated perfused liver. Hepatology, 18: 380-388.

29. LaI, C. and Komarov, A.M. 1994. Spin trapping of nitric oxide produced in vivo in septic-shock mice. FEBS Lett., 345: $120-124$.

30. Lehninger, A.L. 1964. The mitochondrion. New York, W.A. Benjamin INC.

31. LoWENSTEIN, C.J. and SNYDER, S.H. 1992. Nitric oxide, a novel biologic messenger. Cell, 70: 705-707.

32. Michetti, M., Salamino, F., Melloni, E., and Pontremoli, S. 1995. Reversible inactivation of calpain isoforms by nitric oxide. Biochem. Biophys. Res. Commun., 207: 1009-1014.

33. Moncada, S., Palmer, R.M., and Higgs, E.A. 1991. Nitric oxide: physiology, pathophysiology, and pharmacology. Pharmacol. Rev., 43: 109-142.

34. OKada, S., Takehara, Y., Yabuki, M., Yoshioka, T., YASUdA, T., InOUe, M., and Utsumi, K. 1996. Nitric oxide, a physiological modulator of mitochondrial function. Physiol. Chem. Phys. and Med. NMR, in press.

35. PaCker, L., Utsumi, K., and Mustafa, M.G. 1966. Oscillatory states of mitochondria I. Arch. Biochem. Biophys., 117: 381393.

36. PARK, J.W. 1988. Reaction of S-nitrosoglutathione with sulfhydryl groups in protein. Biochem. Biophys. Res. Commun., 152: 916-920.

37. Radi, R., Rodriguez, M., Castro, L., and Teller, R. 1994. Inhibition of mitochondrial electron transport by peroxynitrite. Arch. Biochem. Biophys., 308: 89-95.

38. Richter, C., Gogvadze, V., Schlapbach, R., Schweizer, M., and SCHLEGEL, J. 1994. Nitric oxide kills hepatocytes by mobilizing mitochondrial calcium. Biochem. Biophys. Res. Commun., 205: 1143-1150.

39. SChWizer, M. and Richter, C. 1994 . Nitric oxide potently and reversibly deenergizes mitochondria at low oxygen tension. Biochem. Biophys. Res. Commun., 204: 169-175.

40. Stadler, J., Billiar, T.R., Curran, R.D., Stuehr, D.J., OchoA, J.B., and Simmons, R.L. 1991. Effect of exogenous and endogenous nitric oxide on mitochondrial respiration of rat hepatocytes. Am. J. Physiol., 260: C910-916.

41. Stadler, J., Curran, R.D., Ochoa, J.B., Harbrecht, B.G., Hoffman, R.A., Simmons, R.L., and Billiar, T.R. 1991. 
Effect of endogenous nitric oxide on mitochondrial respiration of rat hepatocytes in vitro and in vivo. Arch Surg., 126: 186191.

42. Stamier, J.S. 1994. Redox signaling: Nitrosylation and related target interactions of nitric oxide. Cell, 78: 931-936.

43. Takehara, Y., Kanno, T., Yoshioka, T., Inoue, M., and UtsUMI, K. 1995. Oxygen-dependent regulation of mitochondrial energy metabolism by nitric oxide. Arch. Biochem. Biophys., 323: $27-32$.

44. TuCKer, S.D., Auzenne, E.J., and Sivaramakrishnen, M.R. 1993. Inhibition of tumor cell mitochondrial respiration by macrophage cytotoxic mediators distinct from interferon- $\gamma$. $J$. Leukocyt. Biol., 53: 138-143.
45. Torres, J., Darley-Usmar, V., and Wilson, M.T. 1995. Inhibition of cytochrome c oxidase in turnover by nitric oxide: mechanism and implications for control of respiration. Biochem. J., 312, in press.

46. TURrens, J.F. and Boveris, A. 1980. Generation of superoxide anion by the NADH dehydrogenase of bovine heart mitochondria. Biochem. J., 191: 421-427.

47. Wharton, M., Granger, D.L., and Durack, D.T. 1988. Mitochondrial iron loss from leukemia cells injured by macrophages. A possible mechanism for electron transport chain defects. J. Immunol., 141: 1311-1317.

(Received for publication, June 18, 1996 and in revised form, July 27, 1996) 